\title{
A comment on the use of Nass's contingency test for random association of alleles at different loci
}

\author{
A. L. Mallet* and \\ E. Zouros ${ }^{\dagger}$
}

\author{
* Fisheries and Oceans, Marine Ecology Laboratory, \\ Bedford Institute of Oceanography, P.O. Box 1006, \\ Dartmouth, N.S., Canada, B2Y 4A2 \\ $\dagger$ Department of Biology, Dalhousie University, \\ Halifax, N.S. Canada, B3H 4J1
}

A $\chi^{2}$ test developed by Nass (1959) and recently used by Ahmad and Hedrick (1985) for the detection of non-random association between alleles of different loci is very sensitive to misclassification of genotypes.

The analysis of electrophoretic data often requires the testing of random associations of alleles among loci to allow inferences about gametic disequilibrium and population subdivisions. The data to be tested involve mutiallelic loci with many rare alleles which lead to contingency tables with very small expectations. To avoid this problem, the usual practice has been either to exclude or to pool frequencies of rare alleles. This practice is however undesirable since rare alleles may provide more information about levels of gene flow among sub- populations than the more common ones (Slatkin, 1985).

Nass (1959) developed a $\chi^{2}$ test for small expectations in contingency tables which was used by Ahmad and Hedrick (1985) to test for random associations of alleles between two loci in natural population of the blue mussel, Mytilus edulis. They found no evidence for association. We also applied this test in a sample of 2-yr-old mussels, Mytilus edulis, for the same purpose (Zouros et al., submitted). 376 mussels were scored for seven

Table 1 Upper diagonal matrix, $\mathrm{N}=374$; Lower diagonal matrix, $\mathrm{N}=376$. Three numbers are shown for each entry. The first number is the Chi-square value, then the degree of freedom, and finally, the probability

\begin{tabular}{|c|c|c|c|c|c|c|c|}
\hline & AP1 & AP2 & PGI & PGM & LAP1 & LAP2 & $\mathrm{OcDH}$ \\
\hline \multirow[t]{3}{*}{ AP1 } & \multirow{3}{*}{-} & $29 \cdot 0$ & $45 \cdot 6$ & $16 \cdot 7$ & $2 \cdot 1$ & $8 \cdot 3$ & $1 \cdot 8$ \\
\hline & & $22 \cdot 0$ & $48 \cdot 0$ & $19 \cdot 0$ & $3 \cdot 0$ & $14 \cdot 0$ & $3 \cdot 0$ \\
\hline & & 0.144 & 0.569 & 0.607 & 0.544 & 0.875 & 0.624 \\
\hline \multirow[t]{3}{*}{ AP2 } & $22 \cdot 9$ & \multirow[t]{3}{*}{-} & $56 \cdot 4$ & $41 \cdot 8$ & $3 \cdot 1$ & $17 \cdot 5$ & $4 \cdot 5$ \\
\hline & $12 \cdot 0$ & & $66 \cdot 0$ & $28 \cdot 0$ & $5 \cdot 0$ & $18 \cdot 0$ & 6.0 \\
\hline & 0.003 & & 0.794 & 0.045 & 0.688 & 0.487 & 0.486 \\
\hline \multirow[t]{3}{*}{ PGI } & $67 \cdot 1$ & $35 \cdot 0$ & \multirow[t]{3}{*}{ - } & $69 \cdot 8$ & $9 \cdot 5$ & $51 \cdot 1$ & $12 \cdot 3$ \\
\hline & $43 \cdot 0$ & $37 \cdot 0$ & & $64 \cdot 0$ & $11 \cdot 0$ & $44 \cdot 0$ & $13 \cdot 0$ \\
\hline & 0.001 & 0.562 & & 0.289 & 0.554 & 0.215 & 0.501 \\
\hline \multirow[t]{3}{*}{ PGM } & $29 \cdot 9$ & $21 \cdot 0$ & $90 \cdot 1$ & \multirow[t]{3}{*}{-} & $2 \cdot 1$ & $23 \cdot 5$ & $5 \cdot 6$ \\
\hline & $18 \cdot 0$ & $16 \cdot 0$ & $55 \cdot 0$ & & $4 \cdot 0$ & $18 \cdot 0$ & $5 \cdot 0$ \\
\hline & 0.004 & 0.179 & 0.002 & & 0.719 & 0.173 & 0.347 \\
\hline \multirow[t]{3}{*}{ LAP1 } & $2 \cdot 6$ & $1 \cdot 6$ & $9 \cdot 8$ & $2 \cdot 8$ & \multirow[t]{3}{*}{-} & $1 \cdot 5$ & $2 \cdot 1$ \\
\hline & $3 \cdot 0$ & $3 \cdot 0$ & 10.0 & $4 \cdot 0$ & & $3 \cdot 0$ & 1.0 \\
\hline & 0.452 & 0.664 & 0.460 & 0.587 & & 0.680 & 0.143 \\
\hline \multirow[t]{3}{*}{ LAP2 } & $14 \cdot 4$ & $39 \cdot 5$ & $54 \cdot 4$ & $25 \cdot 5$ & 1.9 & \multirow[t]{3}{*}{-} & $5 \cdot 1$ \\
\hline & $17 \cdot 0$ & $14 \cdot 0$ & $47 \cdot 0$ & $21 \cdot 0$ & $4 \cdot 0$ & & $3 \cdot 0$ \\
\hline & 0.638 & 0.000 & $0 \cdot 212$ & 0.227 & 0.754 & & $0 \cdot 161$ \\
\hline \multirow[t]{3}{*}{$\mathrm{OcDH}$} & $4 \cdot 7$ & $22 \cdot 9$ & $11 \cdot 7$ & $4 \cdot 7$ & $1 \cdot 8$ & $17 \cdot 2$ & - \\
\hline & $3 \cdot 0$ & $3 \cdot 0$ & $11 \cdot 0$ & $4 \cdot 0$ & $1 \cdot 0$ & $4 \cdot 0$ & \\
\hline & $0 \cdot 197$ & 0.000 & 0.384 & 0.322 & 0.175 & 0.002 & \\
\hline
\end{tabular}


polymorphic loci with number of alleles varying from 4 to 8 . We found that the probability for random association was less than 0.05 in six of the 21 pair-wise combinations of loci (table 1, lower diagonal matrix) suggesting that significant levels of association existed among alleles at different loci. A closer examination of the data showed two possible cases of genotype misclassification. The elimination of two animals from the data set made all the previously significant chi-square values nonsignificant and produced one new significant value table 1, upper diagonal matrix). This latter result suggests that association did not exist in our sample. Exclusion of rare alleles (frequency $<0.01$ ) from our sample also produced no evidence for such association.

In the original application of his test, Nass used cases in which misclassification was impossible. This is however a real possibility in electrophoretic studies. As a result of this, both Type I and Type II error are possible. Type I error will result when common genotypes are misclassified as rare ones or when one rare genotype is misclassified as another rare genotype. Type II errors will result when rare genotypes are missclassified as common ones. Thus, this test should be applied when genotypes are scored without errors or when the experimenter can subsequently rescored his material.

\section{REFERENCES}

AHMAD, M. AND HEDRICK, P.W. 1985. Electrophoretic variation in common mussel, Mytilus edulis: random association of alleles at different loci. Heredity, 55, 47-51.

NASs, C. A. (i. 1959. The $\chi^{2}$ test for small expectations in contingency tables, with special reference to accidents and absenteeism. Biometrika, 46, 365-485.

SLATKIN, M. 1985. Rare alleles as indicators of gene flow. Evolution, 39, 53-65.

ZOUROS, E., ROMERO-DOREY, M. ANI) MALLEI, A, L. 1986. Heterozygosity and growth in marine bivalves: further data and the associative overdominance explanation. Evolution submitted. 